\title{
Comparison of the dental health of adults and children living in NSW with their counterparts in the US and UK
}

\author{
Anthony S. Blinkhorn \\ Faculty of Dentistry, University of Sydney \\ Email:ablinkhorn@usyd.edu.au
}

\begin{abstract}
This paper aims to place the findings of the NSW Adult and Child Dental Health Surveys in an international context. The comparator countries are the US and the UK, both of which have well-documented epidemiological dental health data. The US has a mainly private system of dental care, similar to NSW, whereas the UK has primarily a government-funded dental care program. The adult data collected in the last 20 years in all three locations indicates greatly improved oral health with a decline in the proportions of people with no natural teeth. The majority of children have few dental problems but inequality remains with some children in lower socioeconomic groups still having high levels of dental ill health, which contributes to a lower quality of life. Improving population levels of oral health in all three countries will require collective decisionmaking by stakeholders and politicians to finance plans for action and manage change to help those individuals for whom dental disease is still a major problem.
\end{abstract}

Over the past two decades there has been a considerable decline in the dental caries experience of 5- and 12-year-old children in most industrialised countries. ${ }^{1,2}$ However, the quality of much of the dental epidemiological data is somewhat dubious making comparisons difficult. Australia, the United States (US) and the United Kingdom (UK) have well-established epidemiological programs recording the dental health of both adults and children.

A number of host and environmental factors are related to an individual's caries experience. ${ }^{3}$ These factors include age, gender, dietary intake, fluoride exposure, dental attendance patterns, socioeconomic status and rural or urban location. There is evidence from longitudinal studies in the UK that the rapid market penetration of fluoride toothpaste changed the caries experience of children as did the fluoridation of public water supplies in Australia. ${ }^{4}$

The objective of this paper is to compare the dental health of children and adults living in New South Wales (NSW), the US and the UK using data from well-described epidemiological studies.

\section{Methods}

Data from national adult and child surveys in the UK were extracted and compared with NSW data collated by the Australian Research Centre for Population Oral Health (ARCPOH) at the University of Adelaide and data from the US National Health and Nutrition Examination Survey 2003-2004. ${ }^{5-8}$

Details of the UK and US studies have been well documented elsewhere. NSW data were drawn from the Australian National Survey of Adult Oral Health, which was undertaken from 2004 to 2006 and the NSW Child Dental Health Survey that examined children in $2007 .^{7-9}$

\section{Results}

\section{Adults}

The proportions of people who were classified as having lost all of their natural teeth (edentulous) are presented in Table 1. Levels of total tooth loss were of little clinical significance for people aged under 35 years. NSW had the lowest prevalence of total tooth loss within every age category except for adults aged 75 years and over. Both the US and NSW fared much better than the UK.

Table 2 presents the mean number of missing teeth per person in each location according to age. The NSW and US participants have similar levels of tooth loss, much lower than that recorded by the UK. The NSW and US surveys had similar proportions of participants with one or more decayed (carious) teeth; the percentages were approximately half that reported by the UK Adult Dental Health Survey (Table 3). ${ }^{6,8}$

\section{Children}

The data for children were confined to 5-6-year olds and 11-12-year olds as these age groups are used by the World 
Table 1. Proportion of adults in the UK, NSW and US who are edentulous, according to age

\begin{tabular}{lcccc}
\hline Age & $\begin{array}{c}\text { United Kingdom* } \\
\%\end{array}$ & Age & $\begin{array}{c}\text { New South Wales } \\
\%\end{array}$ & $\begin{array}{c}\text { United States } \\
\%\end{array}$ \\
\hline $16-24$ & 0 & & 0 & 0 \\
$25-34$ & 0 & $20-34$ & 1 & 3 \\
$35-44$ & 1 & $35-49$ & & 10 \\
$45-54$ & 6 & $50-64$ & 20 & 24 \\
$55-64$ & 20 & $65-74$ & 36 & 31 \\
$65-74$ & 36 & $75+$ & & \\
$75+$ & 58 & &
\end{tabular}

Table 2. The mean number of missing teeth of adults in the UK, NSW and US, according to age

\begin{tabular}{|c|c|c|c|c|}
\hline Age & $\begin{array}{c}\text { United Kingdom } \\
\%\end{array}$ & $\begin{array}{c}\text { New South Wales } \\
\%\end{array}$ & Age* & $\begin{array}{c}\text { United States } \\
\%\end{array}$ \\
\hline $16-24$ & 4.1 & 0.6 & 16-19 & 0.1 \\
\hline $25-34$ & 3.9 & 1.0 & $20-34$ & 0.6 \\
\hline $35-44$ & 5.3 & 2.1 & $35-49$ & 2.4 \\
\hline $45-54$ & 8.0 & 5.9 & $50-64$ & 5.3 \\
\hline $55-64$ & 12.1 & 9.1 & & \\
\hline $65+$ & 14.7 & 12.8 & $65-74$ & 8.3 \\
\hline \multicolumn{5}{|c|}{$\begin{array}{l}\text { *United States age categories are not a direct match. } \\
\text { Sources: Adult Dental Health Survey. London: Office for National Statistics; } 2000{ }^{6} \text { The National Survey of Adult } \\
\text { Oral Health 2004-06. Canberra: AlHW; 2007.7 Trends in oral health status: United States } 1988-1994 \text { and } \\
\text { 1999-2004. }\end{array}$} \\
\hline
\end{tabular}

Table 3. Proportion of adults in the UK, NSW and US with one or more carious teeth, according to age

\begin{tabular}{lcccc}
\hline Age & $\begin{array}{c}\text { United Kingdom } \\
\%\end{array}$ & $\begin{array}{c}\text { New South Wales } \\
\%\end{array}$ & Age* & $\begin{array}{c}\text { United States } \\
\%\end{array}$ \\
\hline $16-24$ & 51 & 24 & $16-19$ & 18 \\
$25-34$ & 60 & 27 & $20-34$ & 28 \\
$35-44$ & 51 & 30 & $35-49$ & 26 \\
$45-54$ & 57 & 24 & $50-64$ & 22 \\
$55-64$ & 54 & 23 & $65-74$ & 20 \\
$65+$ & 54 & 22 & & \\
*United States age categories are not a direct match. \\
Sources: Adult Dental Health Survey. London: Office for National Statistics; 2000. ${ }^{6}$ The National Survey of Adult Oral \\
Health 2004-06. Canberra: AlHW; 2007. ${ }^{7}$ Trends in oral health status: United States 1988-1994 and 1999-2004.
\end{tabular}

Health Organization (WHO) in their pathfinder database. The US data are more difficult to unravel as 2-5-year-olds are grouped, which is a disadvantage as dental caries increases over time. Including younger children in the age group will lower the mean $\mathrm{dmft}$ (decayed, missing due to caries, filled teeth) index.
Table 4 shows that the UK and NSW have similar mean dmft scores, with the US slightly lower at 1.1; for reasons already stated, this score may be an underestimate.

The data presented in Table 5 detail the mean DMFT scores for 11-12-year-old children. Once again, comparisons 
Table 4. Mean dmft and caries experience of 5-6-year-old children in NSW, the UK and the US

\begin{tabular}{|c|c|c|}
\hline & $\mathrm{dmft}$ & $\%$ caries free \\
\hline New South Wales & 1.6 & 60 \\
\hline United Kingdom & 1.5 & 57 \\
\hline United States (2-5-year-olds)* & 1.1 & 70 \\
\hline \multicolumn{3}{|c|}{$\begin{array}{l}{ }^{*} \text { A different age range was used in the United States. } \\
\text { dmft }=\text { decayed, missing due to caries and filled teeth index for } \\
\text { primary (baby) teeth. } \\
\text { Sources: The Child Dental Health Survey, NSW } 2007 . \text { Centre for Oral } \\
\text { Health Strategy. }{ }^{9} \text { Trends in oral health status: United States } \\
\text { 1988-1994 and } 1999-2004 .{ }^{8} \text { Children's Dental Health in the United } \\
\text { Kingdom. London:The Stationery Office; } 2003 .{ }^{13}\end{array}$} \\
\hline
\end{tabular}

Table 5. Mean DMFT and caries experience of 11-12-yearold children in NSW, the UK and the US

\begin{tabular}{lcc}
\hline & DMFT & \% caries free \\
\hline New South Wales & 0.80 & 64 \\
United Kingdom & 1.00 & 69 \\
United States (12-15-year-olds)* & 1.67 & 49
\end{tabular}

${ }^{*}$ A different age range was used in the United States.

DMFT $=$ Decayed, Missing due to caries, Filled Teeth index for permanent (adult) teeth.

Sources: The Child Dental Health Survey, NSW 2007. Centre for Oral Health Strategy. ${ }^{9}$ Trends in oral health status: United States 1988-1994 and 1999-2004. ${ }^{8}$ Children's Dental Health in the United Kingdom. London: The Stationery Office; $2003 .{ }^{13}$

cannot easily be made with the US data due to differences in the age categories used. The inclusion of older children in the age group will inflate the DMFT score. NSW has achieved a mean score of under 1 , which is less than the UK and the US.

\section{Discussion}

International comparisons of dental data are fraught with difficulty, but Australian, UK and US researchers use similar systems and dental epidemiology, as an academic specialty, is well developed in each of these countries. Therefore, broad conclusions about dental health can be made with some confidence. Earlier epidemiological studies have shown that there have been international improvements over time in dental health in all age groups. ${ }^{8}$ For example, since 1974-1994 there was a decrease of $44 \%$ in the carious surfaces of 18-25-year-old US adults. Milgrom and Reisine have reviewed improvements in dental health in the US but warn of the difficulties in overcoming the dental problems of poor communities. ${ }^{10,11}$ Changes in total tooth loss over time in Australia have also showed considerable improvement. ${ }^{12}$

In the UK, for example, the mean DMFT in 12-year-olds declined from 3.1 in 1973 to 0.8 in 2003 and in Australia from 4.8 in 1977 to 1.1 in $1993 . .^{13,14}$ This reduction in decay (caries) levels has been accompanied by a change in the distribution of carious lesions; the relative contribution of pit and fissure caries to overall disease levels has increased. ${ }^{1,15}$ Dental caries appears to have changed from a rapidly progressing disease of childhood to a slowly progressing disease in adulthood. ${ }^{16}$ There is an argument that these improvements may be transitory, with a possibility that the situation could reverse. Declines in dental caries among young children may have stabilised and there may even be a marginal increase in prevalence. This situation may be simple biological variation, but it does mean that countries with water fluoridation should ensure it continues to operate efficiently and the UK will need to speed up its plans for more widespread fluoridation schemes.

The improvements in dental health are also linked to changes in how the public perceive the health of their teeth. White smiles and teeth in regular alignment are now seen as crucial social attributes. This has put pressure on orthodontic services and seen an explosion in cosmetic dentistry. A greater number of natural teeth also means people need more regular maintenance therapy. The improvement in dental health has therefore not reduced the need for treatment services.

The resources spent by governments on dental care in the three comparator locations are different because of the split between private and public funding. The UK has developed a model of care linked closely to government funding while NSW and the US have a predominantly private sector system of care. However, both the US and Australia have to recognise that their systems disenfranchise many people from dental care. The public dental services in both countries do not have the resources to offer continuing oral health care to patients, which denigrates dental professionals who become emergency-only operators rather than highly trained and skilled clinicians. While the dental health of all three locations is similar, the epidemiological snapshot hides an iceberg of patient discontent and inequality of care among deprived communities. ${ }^{17,18}$

The data presented show that the dental health of adults and children in NSW is as good as their counterparts in the US and UK, while the data on total tooth loss highlights a revolution in NSW dental health with the loss of all teeth and the need for a full set of dentures becoming a historical quirk of fate rather than a common occurrence for the rising generations of younger Australians (Table 1).

\section{Conclusion}

The dental health of children and adults in NSW is as good as, and in some cases better than, similar populations in the US and the UK. However, any improvements are fragile and need nurturing, especially in terms of maintaining the highly successful water fluoridation program, 
which has done much to help the majority of NSW residents have healthy mouths. ${ }^{19,20}$

\section{References}

1. Marthaler TM. Changes in dental caries 1953-2003. Caries Res 2004; 38: 173-81. doi:10.1159/000077752

2. Peterson PE. Continuous improvement of oral health in the 21 st Century - the approach of the WHO Global Oral Programme. The World Health Report. Geneva: World Health Organization, 2003.

3. Eriksen HM, Vladimir D. Ecology of oral health: a complexity perspective. Eur J Oral Sci 2003; 111: 285-90. doi:10.1034/j.1600-0722.2003.00053.x

4. Downer MC. Changing pattern of dental disease over 50 years. Br Dent J 1998; 185: 36-41. doi:10.1038/sj.bdj.4809721

5. Pitts H, Harker R. Children's Dental Health in the United Kingdom 2003. London: Office for National Statistics; 2004.

6. Kelly M, Steel J, Nuttal N, Bradnock G, Morris J, Nunn J et al. Adult dental health survey: Oral health in the United Kingdom in 1998. London: Office for National Statistics; 2000.

7. Slade GD, Spencer AJ, Roberts-Thomson KF, editors. Australia's dental generations: the National Survey of Adult Oral Health 2004-06. Dental Statistics and Research Series No. 34. Canberra: Australian Institute of Health and Welfare; 2007.

8. Dye BA, Tan S, Smith V, Lewis BG, Barker LK, ThorntonEvans G et al. Trends in oral health status: United States 19881994 and 1999-2004. Vital Health Stat 11 2007; 248: 1-92.

9. Phelan C, Byun R, Skinner JC, Blinkhorn AS. Child Dental Health Survey 2007: a snapshot of the oral health status of primary school-aged children in NSW. NSW Public Health Bull 2009; 20(3-4): 40-5.

10. Brown JL, Wall TP, Lazar V. Trends in caries among adults 18-45 year old. J Am Dent Assoc 2002; 133: 827-34.
11. Milgrom P, Reisine S. Oral Health in the United States: The Post-Fluoride Generation. Annu Rev Public Health 2000; 21: 403-36. doi:10.1146/annurev.publhealth.21.1.403

12. Sanders AE, Slade GD, Carter KD, Stewart JF. Trends in the prevalence of complete tooth loss amongst Australians, 1979-2002. Aust N Z J Public Health 2004; 83: 661-9.

13. Lader D, Chadwick BM, Chestnutt I, Harker R, Morris J. Children's Dental Health in the United Kingdom. London: The Stationery Office; 2003.

14. Davies MJ, Spencer AJ, Slade GD. Trends in dental caries experience of school children in Australia 1977-1993. Aust Dent J 1997; 42: 389-94.

15. Downer MC, Druggan CS, Blinkhorn AS. Dental caries experience of British children in an international context. Community Dent Health 2005; 22: 86-93.

16. Griffin SO, Griffin PM, Swann JL, Zlobin N. New coronal caries in older adults, implications for prevention. $J$ Dent Res 2005; 84: 715-20. doi:10.1177/154405910508400806

17. Vargas CM, Dye BA, Hayes KL. Oral Health status of rural adults in the United States. JAM Dent Assoc 2002; 133: 672-81.

18. Petersen PE, Bourgeois D, Ogawa H, Estupiñán-Day S, Ngiaye C. The global burden of oral diseases and risks to oral health. Bull World Health Organ 2005; 83: 661-9.

19. Burt BA. Fluoridation and social equity. J Public Health Dent 2002; 61: 195-200.

20. Slade GD, Spencer AJ, Davies MJ, Stewart JF. Influence of exposure to fluoridated water on socioeconomic inequalities in children's caries experience. Community Dent Oral Epidemiol 1996; 24(2): 89-100. doi:10.1111/j.1600-0528.1996.tb00822.x 